\title{
TOLERÂNCIA A BAIXAS TEMPERATURAS DE CULTIVARES DE ABACATE (Persea americana MILL.) ${ }^{1}$
}

\author{
NILBERTO BERNARDO SOARES ${ }^{2}$, MÁRIO JOSÉ PEDRO JÚNIOR ${ }^{2,3}$, LUIZ ANTONIO JUNQUEIRA TEIXEIRA², \\ JAIRO LOPES DE CASTRO ${ }^{3}$
}

RESUMO - Em experimento realizado no Núcleo de Agronomia do Sudoeste/IAC, em Capão Bonito (SP), observou-se o comportamento de 13 cultivares de abacate com seis anos de idade: Geada, Pollock e Simmonds (raça antilhana); Antoniolli, Breda, Campinas, Ermor, Jumbo, Margarida, Ouro verde, Reis e Solano (híbridos de antilhana x guatemalense) e Fuerte (híbrido de mexicana x guatemalense) em relação às baixas temperaturas. As temperaturas do ar registradas no posto meteorológico do local foram: $-2,8^{\circ} \mathrm{C} ;-0,4^{\circ} \mathrm{C} ;-0,2^{\circ} \mathrm{Ce}-1,8^{\circ} \mathrm{C}$, respectivamente, nos dias $17 ; 18 ; 20$ e 21 de julho de 2000. A cultivar Fuerte mostrou-se mais tolerante às baixas temperaturas, não apresentando injúrias nas plantas nem queda de frutos; as cultivares híbridas de antilhana $\mathrm{x}$ guatemalense apresentaram diferenças de tolerância ao frio; enquanto as antilhanas foram severamente injuriadas.

Termos para indexação: raças e híbridos, danos pelo frio, queda de frutos, geada

\section{LOW TEMPERATURE TOLERANCE OF AVOCADO (Persea americana MILL.) CULTIVARS}

ABSTRACT - A field trial carried out at Instituto Agronômico Experiment Farm at Capão Bonito, State of São Paulo, Brazil, observed the behaviour of thirteen avocado cultivars of six years old: Geada, Pollock and Simmonds (West Indian cultivars); Antoniolli, Breda, Campinas, Ermor, Jumbo, Margarida, OuroVerde, Reis and Solano (Guatemalan x West Indian Hybrids) and Fuerte (Guatemalan x Mexican hybrid) in relation to low temperatures occurred at the weather station. The values of the minimum air temperatures recorded were: $-2.8^{\circ} \mathrm{C},-0.4^{\circ} \mathrm{C}$ and $-1.8^{\circ} \mathrm{C}$ on $\mathrm{July} 17^{\text {th }}, 18^{\text {th }}, 20^{\text {th }}$ and $21^{\text {th }}, 2000$ respectively. The Fuerte cultivar was the most tolerant to cold, without injuries on the canopy and fruit drop. The Guatemalan $\mathrm{x}$ West Indian cultivars showed different degrees of cold injury and fruit drop, while the West Indian cultivars were severely damaged by the cold.

Index terms: races and hybrids, cold damage, fruit drop, frost.

\section{INTRODUÇÃO}

O abacateiro, da família lauraceae, subgênero Persea, compreende três espécies: Persea americana var. americana; Persea nubigena var. guatemalensis e Persea americana var. drymifolia, as quais correspondem, respectivamente, às raças hortícolas conhecidas como antilhana, guatemalense e mexicana, que são descritas como tropical, subtropical e semitropical, baseado na sua resistência ao frio e adaptação climática (Campbell \& Malo, 1976; Williams, 1976).

Um dos objetivos do melhoramento genético do abacateiro é selecionar cultivares tolerantes ao frio para sua exploração econômica em áreas sujeitas a geadas. Existe variabilidade de tolerância ao frio entre cultivares dentro de uma raça e grande variabilidade entre cultivares dentre as raças (Bergh \& Lahav, 1996).

Segundo Wolfe et al. (1942), plantas adultas da raça antilhana não suportam temperaturas inferiores a $-4,4^{\circ} \mathrm{C}$ e são injuriadas consideravelmente $\mathrm{a}-2,8^{\circ} \mathrm{C}$, enquanto a maioria das cultivares guatemalenses não suportam temperaturas abaixo de $-6,1^{\circ} \mathrm{C}$, e algumas cultivares mexicanas, muito resistentes, suportam temperaturas inferiores a $-7,7^{\circ} \mathrm{C}$. Krezdorn (1974) concorda com estas afirmações, exemplificando que cultivares antilhanas, como a Waldin, são injuriadas somente por temperaturas entre $-1,1^{\circ} \mathrm{C} \mathrm{e}-1,7^{\circ} \mathrm{C}$, enquanto algumas cultivares mexicanas, como a Mexicola, resistem a temperaturas entre $-8 \mathrm{e}-11^{\circ} \mathrm{C}$, apresentando apenas leves injúrias. Os híbridos entre as duas raças apresentam resistência intermediária.

Segundo Bergh (1975), a cultivar Yama é considerada uma das mais resistentes dentre as mexicanas, suportando temperatura de $-8,5^{\circ} \mathrm{C}$ sem sofrer danos severos.

Knight Jr. (1976) relata que, há muito tempo, a cultivar mexicana Brooksville é utilizada como porta-enxerto, na Flórida, por seus seedlings suportarem frio artifical de $-8,5^{\circ} \mathrm{C}$.

Krezdorn (1974) observou que a cultivar Gainesville suportou temperatura de $-9,4^{\circ} \mathrm{C}$ em plantios comerciais, e Scorza \& Wiltbank (1976) concluíram ser esta a mais resistente cultivar dentre cinco submetidas ao frio artifical. Plantas desta cultivar, formadas por estacas, suportaram, quando adultas, temperaturas de até $-7,8^{\circ} \mathrm{C}$, valor bem superior a $6,7^{\circ} \mathrm{C}$ suportado pelas cultivares Mexicola e Topa-Topa, pertencentes à raça mexicana.
Platt (1975) estabeleceu os limites de tolerância ao frio sob as condições californianas, para as cultivares híbridas de mexicana $\mathrm{x}$ guatemalense: Fuerte, que foi de $-2,8^{\circ} \mathrm{C}$, Bacon, $-3,3^{\circ} \mathrm{C}$ e Zutano, $-4,4^{\circ} \mathrm{C}$.

Toohill \& Alexander (1979) ponderam que a fixação de limites exatos de tolerância ao frio é de difícil demarcação, visto que os danos causados a uma dada cultivar são influenciados pelo grau e duração do frio e pelas condições fisiológicas da planta no momento da ocorrência das baixas temperaturas. Esses autores avaliaram a tolerância relativa de 19 cultivares de abacate submetidas a uma severa geada, durante a qual a temperatura permaneceu abaixo de $0^{\circ} \mathrm{C}$ por $3 \mathrm{~h} 8$ horas e alcançou um mínimo de $-2,3^{\circ} \mathrm{C}$, com a mínima na relva de $-8^{\circ} \mathrm{C}$. Somente duas cultivares, Anaheim e Millicent, foram seriamente danificadas, enquanto as demais, incluindo-se a Fuerte e a Hass, sofreram danos desprezíveis.

O objetivo deste trabalho foi avaliar a tolerância de cultivares de abacate às baixas temperaturas, visando à seleção de genótipos tolerantes para utilização direta, ou como fontes de tolerância ao frio para utilização em programa de melhoramento genético.

\section{MATERIAL EMÉTODOS}

O campo experimental foi instalado em 1994, no Núcleo de Agronomia do Sudoeste/IAC, localizado em Capão Bonito-SP, de coordenadas de $24^{\circ} 00^{\prime} \mathrm{S}$ e $48^{\circ} 22^{\prime} \mathrm{W}, 702 \mathrm{~m}$ de altitude e clima tipo Cfa (clima com chuvas do mês mais seco entre 30 e $60 \mathrm{~mm}$; temperatura do mês mais quente inferior a $22^{\circ} \mathrm{C}$ e temperatura do mês mais frio inferior a $18^{\circ} \mathrm{C}$ ), visando a avaliar o comportamento agrofenológico de 13 cultivares de abacate, com as mudas formadas sobre o porta-enxerto Collinson.

O delineamento experimental utilizado foi o de blocos ao acaso, com quatro repetições e 13 tratamentos (cultivares): Geada, Pollock e Simmonds (raça antilhana); Antoniolli, Breda, Campinas, Ermor, Jumbo, Margarida, Ouro Verde, Reis e Solano (híbridos antilhana x guatemalense) e Fuerte (híbrido mexicana $\mathrm{x}$ guatemalense). $\mathrm{Na}$ análise de variância, empregou-se o Módulo GLM (General Linear Models) do SAS, segundo Freund \& Littell (1981). Para a comparação das médias dos tratamentos, foi utilizado o teste " $\mathrm{t}$ "de Student (á $=0,01)$, com os dados originais transformados por $\sqrt{x \quad 0,05}$

Em julho de 2000, com as plantas atingindo seis anos após o plantio, houve sério resfriamento da temperatura do ar, nos dias $17 ; 18$; 
20 e 21, com os termômetros no abrigo da estação meteorológica local marcando, respectivamente, temperaturas de $-2,8^{\circ} \mathrm{C},-0,4^{\circ} \mathrm{C},-0,2^{\circ} \mathrm{Ce}-$ $1,8^{\circ} \mathrm{C}$, com a ocorrência de geada.

Os danos causados pelo frio foram avaliados, atribuindo-se notas para as injúrias observadas na copa e para queda de frutos. A escala de notas de danos variou de zero a 4 , de acordo com a porcentagem da copa da planta injuriada, e de zero a 2 , de acordo com a porcentagem de frutos caídos ao solo, conforme Tabela 1. As cultivares Breda, Ouro Verde, Geada, Pollock e Simmonds não foram analisadas quanto à queda de frutos; as duas primeiras por apresentarem produções nulas, $\mathrm{e}$ as três últimas, por suas colheitas já terem sido realizadas antes da ocorrência das baixas temperaturas do ar.

O levantamento das injúrias às plantas, assim como a queda dos frutos, foi realizado no dia 10 de agosto de 2000 , sendo que a queda dos frutos foi acompanhada até outubro do mesmo ano, quando normalmente termina a colheita das cultivares tardias. As plantas bastante afetadas pelas baixas temperaturas foram podadas, retirando-se os ramos e galhos queimados e tratando-se os cortes com pasta cúprica

TABELA 1 - Escala de notas de danos causados por baixas temperaturas em cultivares de abacate,de acordo com o grau de injúria à copa e à queda de frutos.

\begin{tabular}{cc}
\hline Nota & Dano \\
\hline a $10 \%$ & Copa sem injúrias \\
20 a $30 \%$ & Copa pouco injuriada \\
$50 \%$ & Copa regularmente injuriada \\
70 a $80 \%$ & Copa com injúria forte \\
$100 \%$ & Copa com imjúria muito forte \\
0 & Queda de frutos ------------ \\
2 & Queda de $50 \%$ dos frutos \\
& Queda de $100 \%$ dos frutos
\end{tabular}

\section{RESULTADOSEDISCUSSÃO}

A região de Capão Bonito, no Sul do Estado de São Paulo, pela latitude e altitude, apresenta $45 \%$ de probalidade de ocorrência de temperaturas inferiores a $2^{\circ} \mathrm{C}$ durante o mês de julho (Camargo et al., 1993). A ocorrência de temperaturas negativas de até $-2,8^{\circ} \mathrm{C}$ permitiu a avaliação de cultivares de abacate em relação a níveis de tolerância às baixas temperaturas.

Na tabela 2, observa-se que o cultivar Fuerte, sem diferir significativamente dos cultivares Jumbo, Ermor e Solano, foi o que apresentou maior tolerância às baixas temperaturas, não se verificando injúria à copa das plantas. Esse resultado é concordante com a literatura (Wolfe et al., 1942; Krezdorn, 1974; Campbell \& Malo, 1976), na qual se relaciona o grau de tolerância ao frio com a raça da cultivar.

Dentre as cultivares híbridas entre as raças antilhanana e guatemalense, a cultivar Jumbo, embora não diferisse significativamente de 'Ermor', 'Solano', 'Antoniolli' e 'Campinas', apresentou menor nível de injúria que 'Margarida', 'Reis' e 'Ouro Verde', mostrando a variabilidade de tolerância ao frio existente dentro das raças e híbridos, como também observado por Bergh (1976).

Não houve diferença entre as cultivares antilhanas Geada, Pollock e Simmonds, quanto à tolerância ao frio, tendo sido as três severamente injuriadas, com a copa das plantas e ramos mais finos totalmente queimada. Porém, elas não diferiram das cultivares híbridas Breda e Ouro Verde, cujas plantas apresentaram grau de injúria semelhante. Este fato pode estar relacionado à predominância de caracteres da raça antilhana nessas duas cultivares. Todas as plantas podadas recuperaram-se, formaram copa e floresceram no ano seguinte.

Com relação à queda de frutos, não foi encontrada diferença estatística entre as cultivares: Antoniolli, Fuerte, Solano, Reis, Jumbo, Margarida e Campinas. Apenas a cultivar Ermor foi estatísticamente diferente das outras, apresentando 100\% de queda de frutos(Tabela 2).

Em média, a cultivar Ermor teve queda de 100\% dos frutos, seguida da cultivar Campinas, cuja queda de frutos ficou em torno de $80 \%$. As cultivares Margarida, Jumbo e Reis tiveram queda de frutos entre 20 e $30 \%$. As cultivares Breda e Ouro Verde não produziram frutos neste ano; e a colheita das cultivares antilhanas Pollock, Simmonds e Geada já havia sido feita antes da ocorrência das baixas temperaturas, não permitindo a avaliação do efeito das baixas temperaturas na queda dos frutos.

TABELA 2- Grau de injúria e queda de fruto de 13 cultivares de abacate devido à baixa temperatura.

\begin{tabular}{|c|c|c|c|c|}
\hline Cultivares & Injúria & & Cultivares & Queda de frutos ${ }^{(2) ;(4)}$ \\
\hline Fuerte & $0,0 \mathrm{a}^{\prime}$ & & Antoniolli & $0,0 \mathrm{a}$ \\
\hline Jumbo & $0,1 \mathrm{a}$ & & Fuerte & $0,0 \mathrm{a}$ \\
\hline Ermor & $0,4 \mathrm{a}$ & & Solano & $0,0 \mathrm{a}$ \\
\hline Solano & $0,7 \mathrm{a}$ & & Reis & $0,4 \mathrm{a}$ \\
\hline Antoniolli & 0,8 & bcd & Jumbo & $0,6 \mathrm{ab}$ \\
\hline Campinas & 1,1 & bcde & Margarida & $0,6 \mathrm{ab}$ \\
\hline Margarida & 1,6 & cde & Campinas & $1,7 \mathrm{ab}$ \\
\hline Reis & 1,7 & $\mathrm{de}$ & Ermor & $2,0 \quad b$ \\
\hline Ouro Verde & 2,6 & ef & & \\
\hline Breda & 3,7 & f & & \\
\hline Geada & 3,9 & $f$ & & \\
\hline Simmonds & 3,9 & $\mathrm{f}$ & & \\
\hline Pollock & 4,0 & f & & \\
\hline CV $(\%)$ & 18 & & & 26 \\
\hline
\end{tabular}

(1) $\mathrm{e}^{(2)}$ severidade da injúria de acordo com a Tabela 1; ${ }^{(3)}$ médias seguidas por letras iguais não diferem pelo teste " $\mathrm{t}$ " $(\mathrm{p}>0,01)$; ${ }^{(4)}$ a queda dos frutos das cultivares Breda, Ouro Verde, Geada, Pollock e Simmonds não foi analisada, porque as duas primeiras não produziram frutos, e a colheita das demais já havia sido feita antes da ocorrência das baixas temperaturas.

\section{CONCLUSÕES}

As cultivares Fuerte, Jumbo, Ermor e Solano mostraram menor grau de injúria na copa. A cultivar Ermor foi a mais afetada pelas baixas temperaturas em relação à queda de frutos. Ainda as cultivares Fuerte e Solano, pelo baixo nível combinado de danos apresentados (injúria mais queda de frutos), são as mais indicadas para a região.

\section{REFERÊNCIASBIBLIOGRÁFICAS}

BERGH, B.O. Avocados. In: JANICK, J.; MOORE, J. N. Advances in fruit breeding. West Lafayette: Purdue University Press, 1975. p. 541-567.

BERGH, B.O. Avocado breeding and selection. In:INTERNATIONAL TROPICAL FRUIT SHORT COURSE: the avocado;1. 1976, Miami Beach. Proceedings... Gainesville: University of Florida, Miami Beach, 1976. p. 24-33.

BERGH, B. O.; LAHAV, E. Avocados. In: JANICK, J.; MOORE. J. N.( Ed.) Fruit breeding: tree and tropical fruits. New York: John Wiley \& Sons, 1996. v.1, p.113-166.

CAMARGO, M. B. P.; PEDRO JÚNIOR, M. J.; ALFONSI, R. R.; ORTOLANI, A. A.; BRUNINI, O. Probabilidade de ocorrência de temperaturas mínimas mensais e anual no Estado de São Paulo. Bragantia, Campinas, v.52, n.2, p.161-168, 1993.

CAMPBELL, C,W.; MALO, S. E. A survey of avocado cultivar. In: INTERNATIONAL TROPICAL FRUIT SHORT COURSE: the avocado. 1., Miami Beach. Proceedings... Gainesville:University of Florida, 1976. p. 24-33. 
FREUND, R. J.; LITTELL, R. C. SAS for linear models: a guide to the ANOVA and GLM procedures. Cary: SAS Institute, 1981. 231p.

KNIGTH, Jr., R. J. Breeding avocados for cold hardiness. In: INTERNATIONAL TROPICAL FRUIT SHORT COURSE: the avocado.,1. Miami Beach, Procceedings... Gainesville:University of Florida, 1976. p.33-36.

KREZDORN, A. H. Influence of rootstock on cold hardiness of avocados. Proceedings of the Florida State Horticultural Society, Winter Haven, v.86, p. 346-348, 1974.

PLATT, R.G. Climate zones of avocado maturity in California. California Avocado Society Yearbook, Los Angeles, v.58, p.49-53, 1975.

SCORZA, R. S.; WILTBANK, W. J. Evaluation of avocado cold hardiness. Proceedings of the Florida State Horticultural Society, Win- ter Haven, v.88, p.496-499, 1975.

TOOHILL, B.L.; ALEXANDER, D. McE. Frost tolerance of 19 avocado cultivars in the Mildura region of the Murray Valley. The Journal of the Australian Institute of Agricultural Science. Oxford, v.45, p. 196-199, 1979.

WILLIAMS, L. O. The botany of the avocado and its relatives International Tropical Fruit Short Course: the avocado. In: INTERNATIONAL TROPICAL FRUIT SHORT COURSE: the avocado.,1., 1976, Miami Beach, Proceedings.. Gainesville:University of Florida. 1976. p. 9-15.

WOLFE, H. S.; TOY, L. R.; STAHL, A. L. Avocado production in Florida. Gainesville: Agricultural Extension Service, 1942.111p. (Bulletin 112) 